\title{
Variation in the trunk musculature of caecilians (Amphibia: Gymnophiona)
}

\author{
Ronald A. Nussbaum \\ Museum of Zoology \\ and \\ Department of Ecology and Evolutionary Biology, The University of Michigan, Ann Arbor, \\ Michigan 48109, U.S.A. \\ AND \\ BRUCE G. NA YLOR \\ Laboratory for Vertebrate Paleontology, Departments of Geology and Zoology, \\ The University of Alberta, Edmonton, Alberta T6G 2E9, Canada
}

(Accepted 13 April 1982)

(With 4 figures in the text)

\begin{abstract}
Variation in the trunk musculature of 28 species of caecilians, representing 24 of the 33 genera and all five families, is summarized. All forms examined have the same muscles in similar positions. Existing variation largely conforms to the current classification of the group, and some variation may be attributable to different modes of locomotion, such as burrowing versus swimming. Caecilian trunk musculature is more similar to that of salamanders than to that of frogs, but the similarity is probably symplesiomorphous. Trunk musculature so far has provided no clues to lissamphibian relationships.
\end{abstract}

\section{Contents}

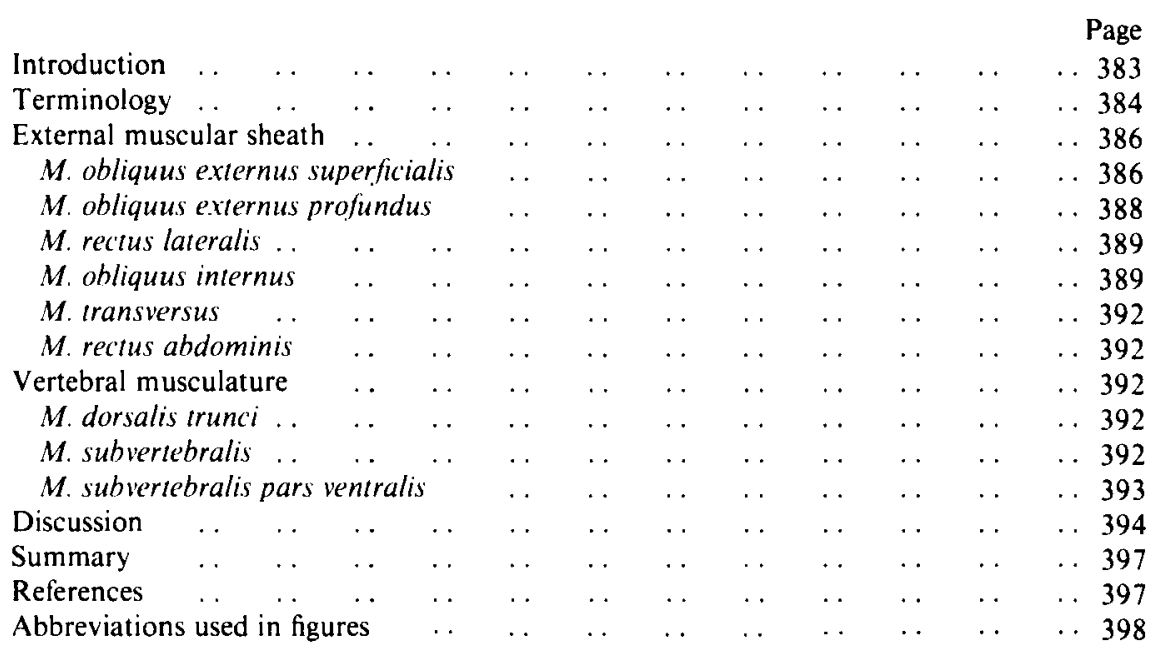

\section{Introduction}

Caecilians are limbless amphibians, entirely dependent upon their trunk musculature for 383 
locomotion. In this regard, caecilians are unique among the modern Amphibia, although some salamanders (Amphiuma, Oedipina, Pseudobranchus, Siren) approach the limbless condition and also rely largely on serpentine undulation for movement. Considering the mode of progression of caecilians, specializations of their trunk musculature and vertebral column are expected, but, surprisingly, morphologists have paid very little attention to the locomotory devices of these unusual animals.

Wiedersheim (1879) provided the first detailed discussion of the trunk musculature of caecilians, based mainly on Caecilia lumbricoides (sic, probably Caecilia gracilis), and concluded that the trunk musculature of caecilians more closely resembles that of other amphibians, especially Amphiuma, than that of snakes. Nishi (1916) compared the trunk musculature of Caecilia pachynema and $C$. tentaculata to that of other vertebrates and decided that caecilian trunk musculature is more highly developed than that of salamanders and more like that of frogs. The first attempt to interpret the function of caecilian trunk muscles was presented by Marcus (1934), but his summary was based largely on the work of his student, which was published the next year (von Schnurbein, 1935). Subsequently, Lawson (1965) described the trunk musculature of Hypogeophis rostratus, and Gaymer (1971) discussed trunk musculature and locomotion in the same species. Gans (1973) criticized Gaymer's interpretation of caecilian locomotion. Naylor \& Nussbaum (1980) compared the trunk musculature of six species representing all five gymnophionan families.

Here we summarize the variation in the trunk musculature of 28 species of caecilians, including species from 24 of the 33 nominate genera, and discuss the taxonomic significance of the variation. The trunk musculature of caecilians is also briefly compared to that of frogs and salamanders.

Recent changes in caecilian systematics are summarized by Nussbaum $(1977,1979)$. UA refers to specimens in the Paleontology collections of the Department of Geology, the University of Alberta, and UMMZ refers to specimens in the Museum of Zoology, the University of Michigan. Methods are described by Naylor \& Nussbaum (1980).

\section{Terminology}

Many of the names of trunk muscles used by Wiedersheim, Nishi, and Lawson are difficult to use because of doubtful homologies or obscure meanings. The names of von Schnurbein were invented by her for use in a strictly functional sense and are inappropriate in the spirit of homologous classification of parts. We have adopted largely the nomenclature of Maurer $(1892,1911)$, which he applied to salamanders in a very cogent manner. This procedure allows us to express directly our views on homology and facilitates comparison of the trunk musculature of caecilians and salamanders. Synonymies are summarized in Table I.

Von Schnurbein (1935) divided the trunk muscles of caecilians into three groups: (1) the trunk musculature proper ("Stamm-Muskulatur"), which included the longitudinal muscles closely associated with the vertebral column (her $M$. vertebralis); (2) the skin musculature ("Haut-Muskulatur"), which includes the outer layer of largely longitudinal muscles adjacent to the skin; and (3) the fascial muscles ("Faszienmuskeln"), which are relatively short, vertically or horizontally oriented muscles. The first group, according to von Schnurbein, bends the vertebral column, the second group bends the skin tube and produces waves of longitudinal contractions, and the third group changes the cross-sectional shape of the body and binds the first and second sets of muscles together. This classification stems from von 


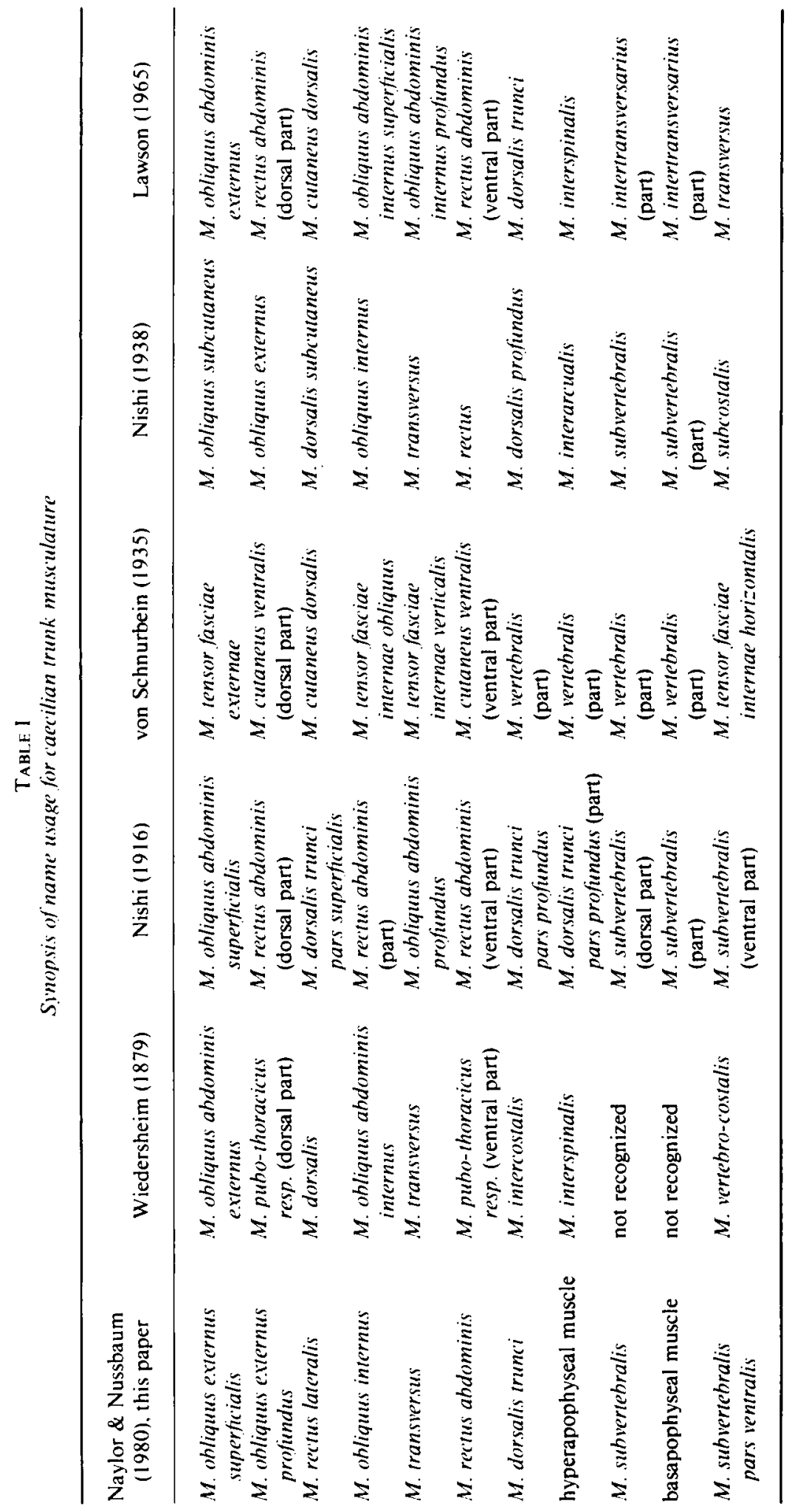


Schnurbein's theories on the function of caecilian trunk muscles in locomotion, theories that are highly speculative and untested. We prefer a two-part classification: (1) external muscular sheath and (2) vertebral musculature, which emphasizes the relative independence of these two groups of muscles in caecilians. The external muscular sheath consists of the $\mathrm{Mm}$. obliquus externus superficialis, obliquus externus profundus, rectus lateralis, obliquus internus, transversus, and rectus abdominis. The vertebral musculature consists of the $M$. dorsalis trunci, hyperapophyseal muscles, $M$. subvertebralis, basapophyseal muscles, and the $M$. subvertebralis pars ventralis. The relative positions of the two sets of muscles are illustrated in Fig. 1.

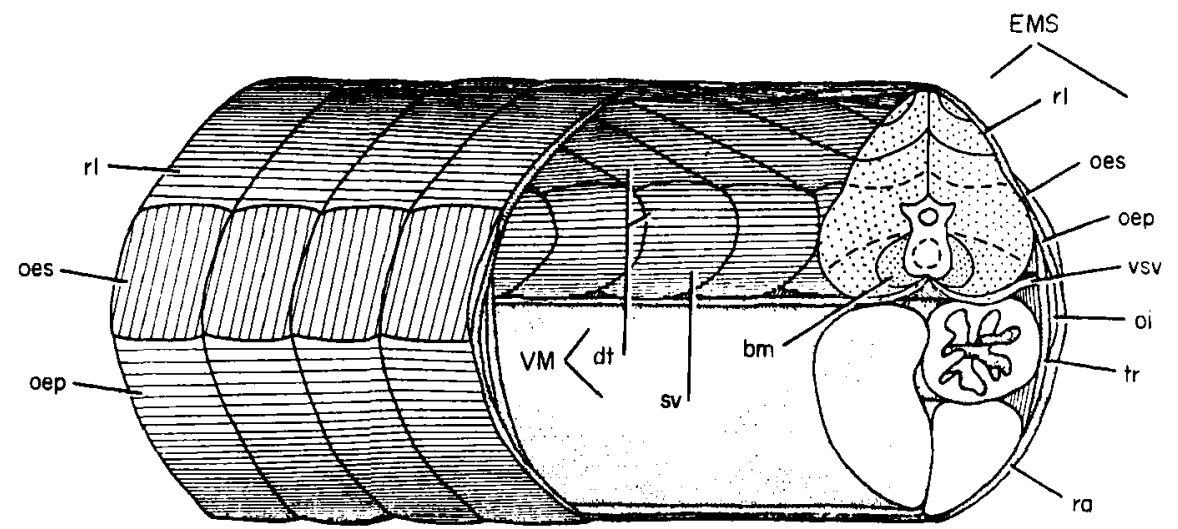

FiG. 1. Diagrammatic illustration showing positions and relationships of caecilian trunk muscles. (Explanation of abbreviations see p. 398.)

\section{External muscular sheath}

Unlike frogs, and more like the situation in many salamanders, the skin of caecilians is bound tightly to the underlying muscles by a dense network of connective tissue. Thus, the skin and the superficial muscles move as a unit. Species in which the skin is divided into primary annuli only, or with some or all of the primary annuli divided into secondary annuli (Caeciliidae, Scolecomorphidae, Typhlonectidae, Uraeotyphlus spp.), have congruent myomeres and primary annuli. No such congruency is evident in species with tertiary annuli (Rhinatrematidae, Ichthyophiidae except Uraeotyphlus spp.).

\section{M. obliquus externus superficialis}

This muscle appears as a very narrow, longitudinal band on each side of the body, just under the skin (Figs 1-3). The short, parallel fibres begin in the tough fascia between the skin and the $M$. rectus lateralis and run ventrally and slightly posteriorly to end in the same fascial sheet between the skin and the $M$. obliquus externus profundus. The fascial sheet that supplies the origin and insertion of the $M$. o. e. superficialis completely encircles the body. The muscle is lenticular in cross-section, and it may or may not be segmented. Where segmentation occurs, the divisions are congruent with the myosepta of the neighbouring muscles. However, the divisions of the $M$. o. e. superficialis are not true myosepta, because the septa of this latter muscle run parallel to the fibres, in contrast to the perpendicular 
(a)

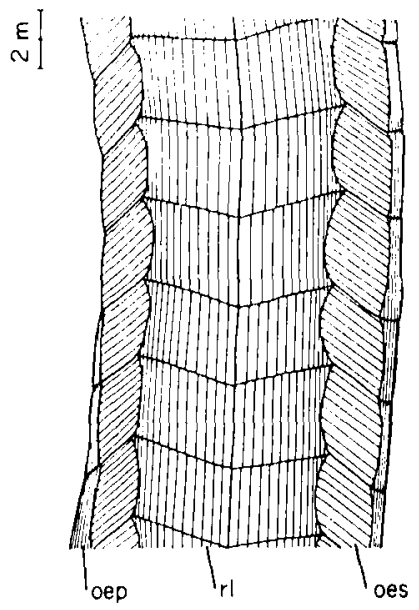

(b)

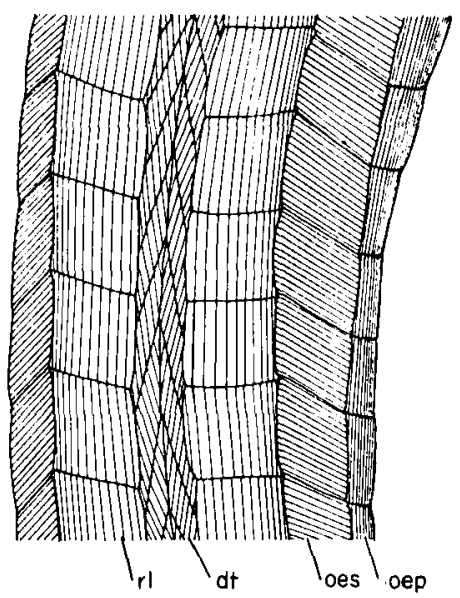

Fig. 2. Dorsal view of trunk musculature, drawn with camera lucida. Muscle fibres shown diagrammatically; (a) Geotrypetes seraphini, UMMZ uncatalogued specimen; (b) Hypogeophis rostratus, UMMZ 145410. (Explanation of abbreviations see p. 398).

arrangement of normal myosepta. It is possible that segmentation of the $M$. o. e. superficialis along the myosepta of the body is related to the mechanical need for separation of the nearly dorsoventrally oriented fibres during lateral flexion of the body. If this is true, then the presence of septa in the $M$. o. e. superficialis of some species has reduced phylogenetic significance. Distinct segmentation is present in rhinatrematids, ichthyophiids, scolecomorphids, and typhlonectids. Among caeciliids, septa in the M. o. e. superficialis may be present, absent with qualification, or absent (Table II). They are clearly present in caeciliids only in the African Geotrypetes seraphini and Schistometopum thomense, and in the Neotropical Caecilia nigricans, Oscaecilia ochrocephala, Dermophis mexicanus, and Siphonops paulensis. In large part, the taxonomic distribution of the states of this character conforms to previous concepts of caecilian relationships, but some uncomformity occurs. For example, segmentation of the $M$. o. e. superficialis may or may not occur within the genus Schistometopum (Table II).

The function of the $M$. obliquus externus superficialis is difficult to interpret, because the fibres are very short and the muscle is very thin. Its universal presence in caecilians, with little variance in position or size, argues that it has a more important basic function than its small size might suggest. Marcus (1934) and von Schnurbein (1935) viewed the M. o.e. superficialis as a "Faszienmuskeln", and thought that it served to decrease the crosssectional area of segments of the body in order to produce irregular surfaces to serve as fixed points for locomotion in burrows. A variety of functions could be hypothesized for this muscle, including hydrostatic action for circulation and locomotion and flattening of the body to increase friction on the sides of burrows, but only careful experimentation will provide the answer.

The $M$. obliquus externus superficialis is often visible externally in preserved specimens that have died with the fibres contracted. The contracted muscle causes the skin immediately above it to bulge outward forming a dorsolateral, longitudinal ridge on each side of the body. 


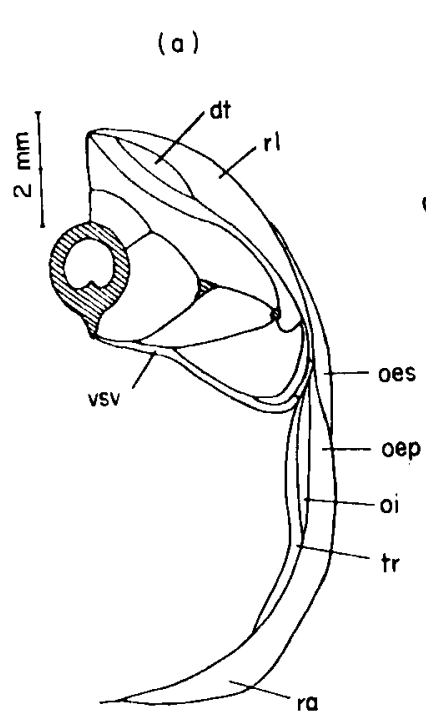

(d) (b)

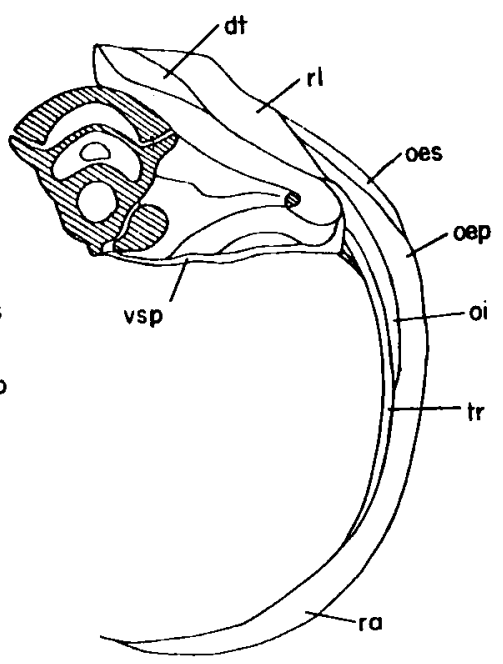

(e) (c)

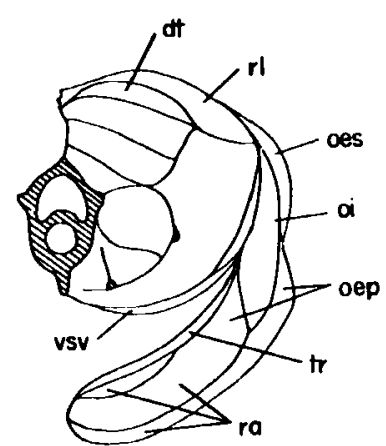

(f)

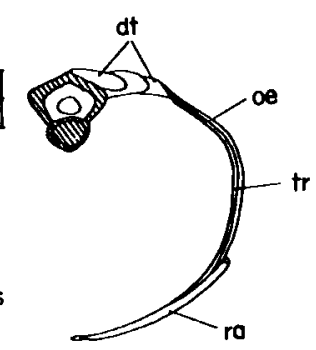

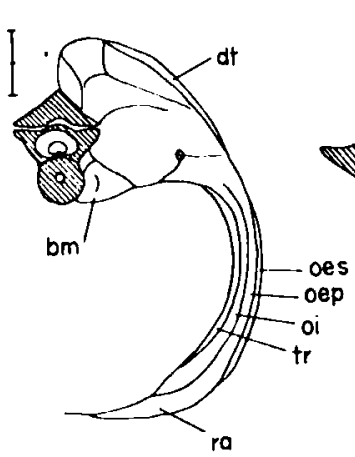

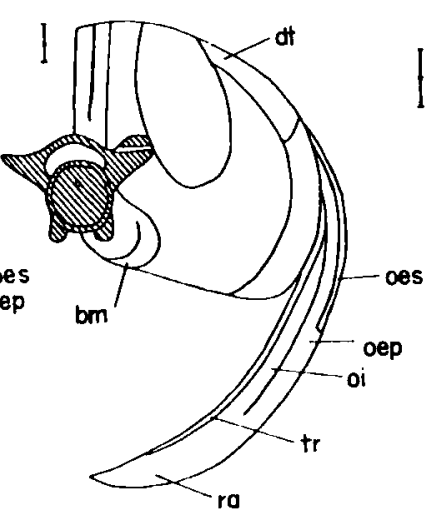

FIG. 3. Cross-sections of trunk musculature drawn with camera lucida; (a) Geotrypetes seraphini, UMMZ uncatalogued specimen; (b) Hypogeophis rostratus, UMMZ 145410; (c) Oscaecilia ochrocephala, UMMZ 76706; (d) Ambystoma tigrinum, UA; (e) Amphiuma means, UA; (f) Rana plaustris, UMMZ uncatalogued specimen. Crosshatching represents bone; stippling represents connective tissue. (Explanation of abbreviations see p. 398. )

These ridges have been described erroneously as diagnostic in certain species. Taylor (1922), for instance, described Ichthyophis glandulosus based in part on this false character.

\section{M. obliquus externus profundus}

This sheet-like, segmented muscle is visible beneath the skin, ventral to the $M$. obliquus externus superficialis (Figs 1-3). Its fibres run longitudinally, between the myosepta. The dorsal-most extent of attachment varies by species. In Hypogeophis rostratus (Fig. 3(b)), the $M$. o. e. profundus extends far dorsally to a point overlying the $M$. rectus lateralis. In this 
species, the dorsal margin of the $M$. o. e. profundus is barely covered by the dorsal part of the M. o. e. superficialis. The M. o. e. profundus does not extend as far dorsally in Geotrypetes seraphini (Fig. 3(a)), in which its dorsal margin lies at the ventral margin of the M. r. lateralis. The dorsal margin of the M. o. e. profundus is even lower in Oscaecilia ochrocephala (Fig. $3(\mathrm{c})$ ), where the margin is separated widely from the $M$. $r$. lateralis, overlies the M. obliquus internus, and lies at the ventral margin of the M. o. e. superficialis. Ventrally, the M. o. e. profundus is continuous with the $M$. rectus abdominis in all species.

In all species examined, except for Epicrionops petersi, there is a marked posterior overlap of the myomeres of the M. obliquus externus profundus. Absence of this posterior overlap may be diagnostic for the Rhinatrematidae.

\section{$M$. rectus lateralis}

The M.r. lateralis is a longitudinal, segmented band of muscle visible just under the skin, dorsomedial to the $M$. obliquus externus superficialis (Figs 1-3). It is present in all caecilians, but significant variation occurs in its positional relationships with other muscles and in the number of posterior and anterior flexures present. In all rhinatrematids, ichthyophiids, scolecomorphids, and typhlonectids examined, the two $\mathrm{Mm}$. $r$. laterales meet middorsally above the vertebral column. This middorsal apposition also occurs in six of 17 species of caeciliids examined (e.g. Fig. 2(a)), but in the remaining 11 species there is a middorsal gap between the two Mm.r. laterales, so that a narrow band of the M. dorsalis trunci is exposed (Fig.2(b)). There is no obvious pattern to this variation within the Caeciliidae, except that the gap occurs in all caeciliids of the Old World tropics except for Geotrypetes seraphini, and, that of the Neotropical species examined, the gap occurs only in Microcaecilia albiceps. It may be significant that there is no gap in the Neotropical typhlonectids, a group possibly derived from Neotropical caeciliids, which also have no gap. The African scolecomorphids also lack a middorsal gap between the $\mathrm{Mm}$. r. laterales, in contrast to most other African caecilians.

Epicrionops petersi has a single posterior and a single anterior, internal flexure in each myomere of the $M$. rectus lateralis. This combination of flexures was seen nowhere else, and may prove to be diagnostic of the family Rhinatrematidae. The five species of ichthyophiids examined had two posterior flexures and one anterior, internal flexure in each myomere of the $M$. r. lateralis, a combination found in no other family. All remaining species examined had a single posterior flexure and no anterior flexures in the $M$. r. lateralis.

In salamanders, the $M$. rectus lateralis, when present, is a narrow band of anteroposteriorly aligned fibres situated immediately below the $M$. dorsalis trunci. The unit is often not clearly separable from the $M$. obliquus externus, except by means of different fibre alignment (Naylor, 1978). The M.r. lateralis is so designated in caecilians because of its relationship to the M. obliquus externus profundus, its intimate association with the lateral abdominal musculature, and its clear separation from the $M$. d. trunci (see also Naylor \& Nussbaum, 1980). The possibility remains, however, that the unit here called the M. r. lateralis is not homologous to the muscle of that name in salamanders, but is derived from superficial fibres of the $M$. d. trunci, or even from some other unit of the lateral abdominal series.

\section{M. obliquus internus}

This muscle lies between the $M$. obliquus externus profundus and the $M$. transversus. It is present in all caecilians with slight positional and size variation, some of which is illustrated in Fig. 3(a)-(c). The fibres of the M. o. internus are nearly vertical, slanting anteroven- 


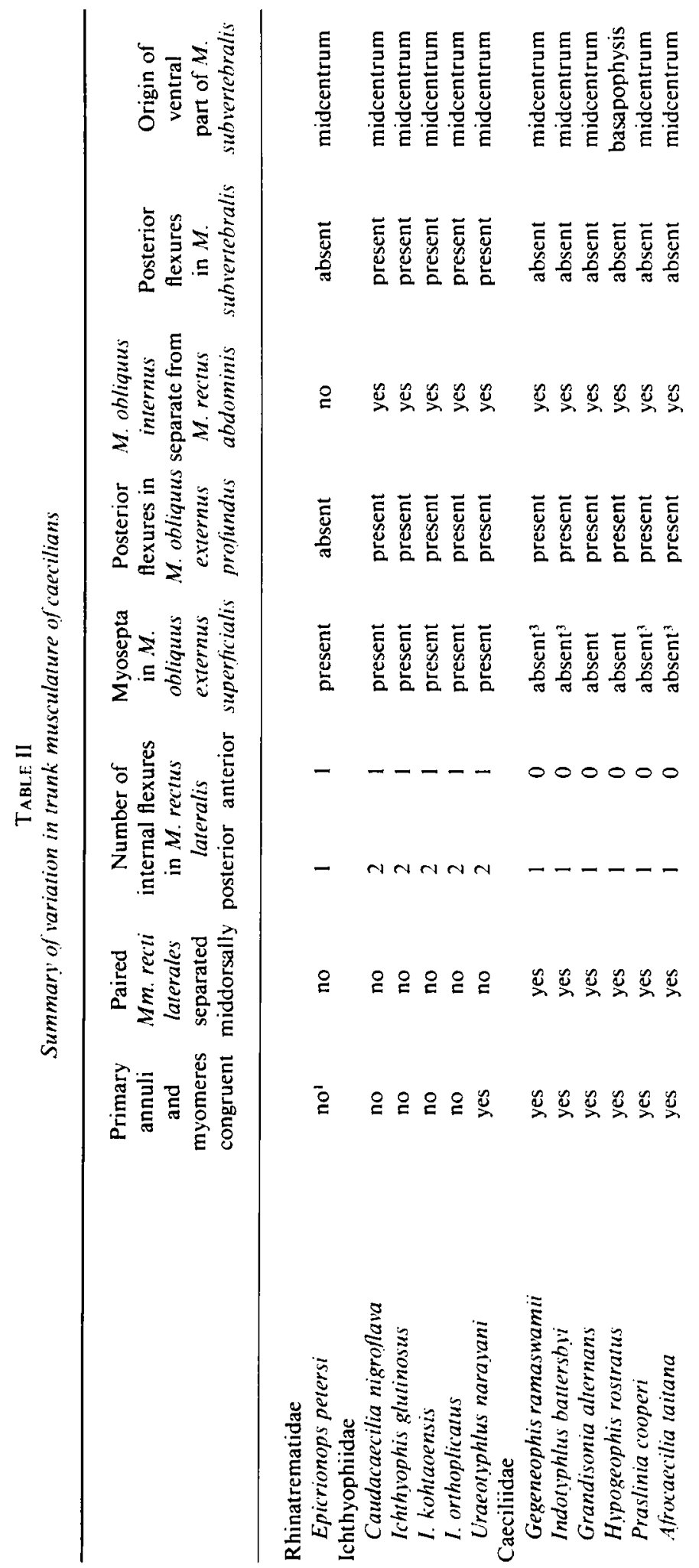




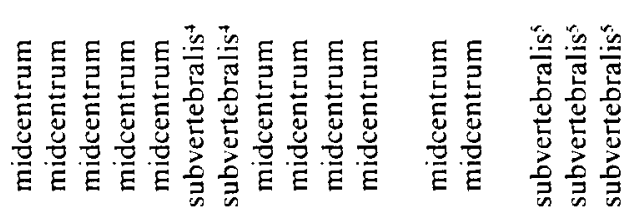

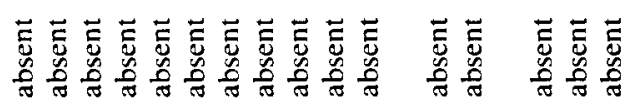

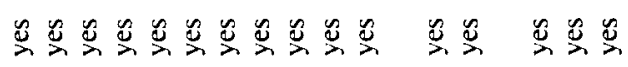

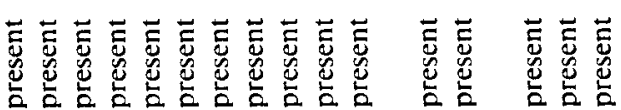

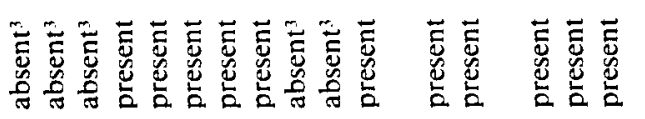

0000000000000000

$-----------\leftarrow$

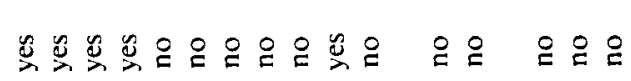

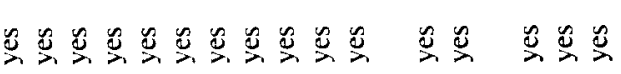
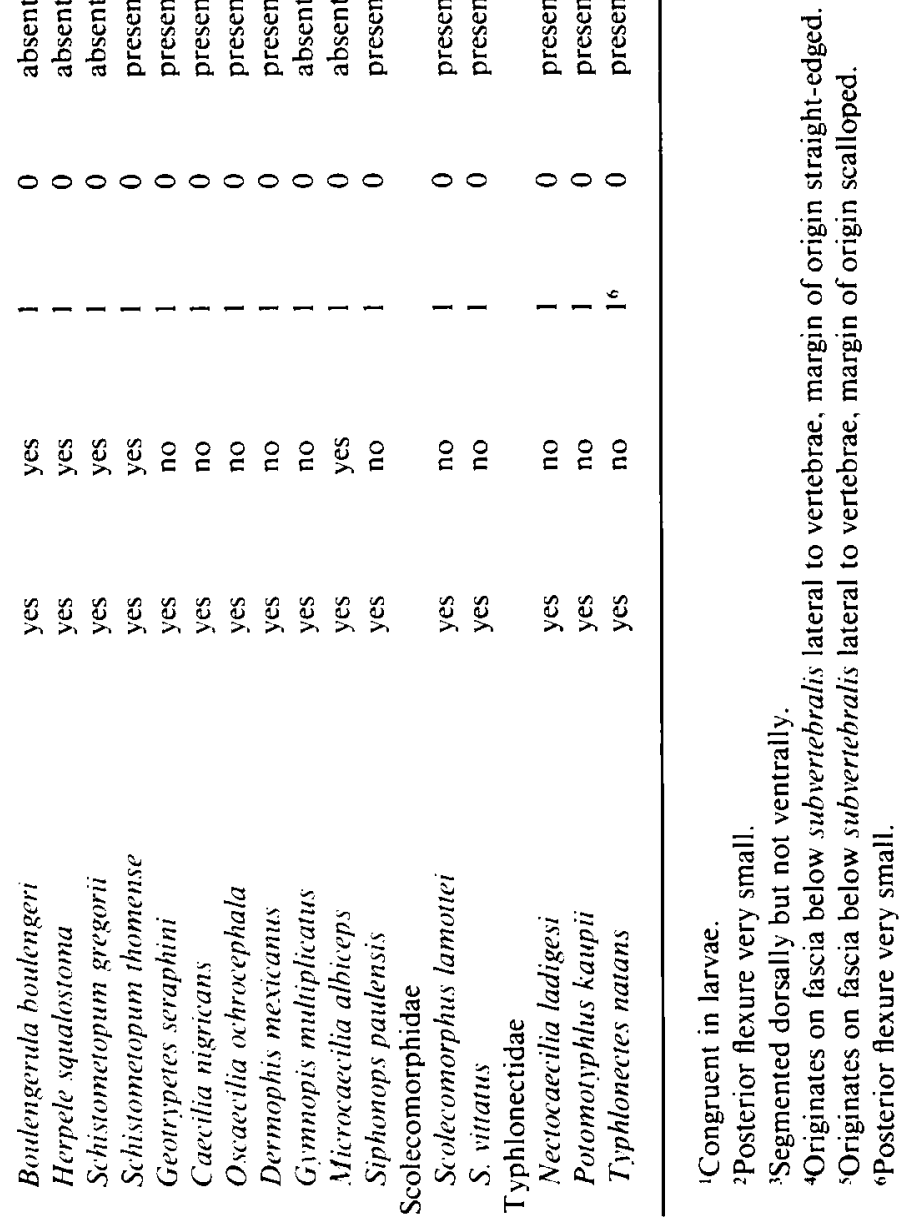
trally at a steep angle from their dorsal origin in fascia on the outer surface of the $M$. dorsalis trunci. The $M$. o. internus of Epicrionops petersi is continuous ventrally with the $M$. rectus abdominis, but is a separate unit in all other species examined. E. petersi is also unique in that its $M$. o. internus is divided by myosepta, whereas this muscle is unsegmented in other forms. These latter two features of $E$. petersi may result from paedomorphosis (Naylor \& Nussbaum, 1980).

\section{M. transversus}

All caecilians have this innermost, sheet-like muscle. Its fibres run dorsoventrally, and it is unsegmented in all species. Dorsally, it attaches via connective tissue to the lateral edge of the pars ventralis of the $M$. subvertebralis, and ventrally, it is attached to the $\mathrm{Mm}$. obliquus externus profundus and rectus abdominis by tough fascia (Fig. 3(a)-(c)). Dorsally, it is applied tightly by connective tissue to the $M$. obliquus internus. Its positional and size relationships are relatively invariant in caecilians.

\section{$M$. rectus abdominis}

This segmented muscle is present in all caecilians. Dorsally, it is continuous with the $M$. obliquus externus profundus, and ventrally, its fibres join the linea alba. Adjacent myomeres of the M. r. abdominis overlap, with each myomere extending over the lateral surface of the next anterior myomere. The overlap is considerable in Caecilia nigricans and Oscaecilia ochrocephala (Fig. 3(c)), but less extensive in the other species.

\section{M. dorsalis trunci}

\section{Vertebral musculature}

There appears to be no significant variation in the $M . d$. trunci at the level studied. In all taxa, the unit is thick and completely covers the vertebrae and ribs. Muscle fibres extend anteroposteriorly between adjacent vertebrae and ribs. Each myomere extends back into an elongate posterior flexure, which influences three intervertebral joints. Muscle fibres fan posteriorly from the apex of each posterior flexure, and the majority of muscle fibres in the $M$. d. trunci are situated in the posterior flexures. Deep to these flexures, paired hyperapophyseal muscles originate over the neural arch of one vertebra and insert by means of a broad aponeurosis to the hyperapophysis of the next anterior vertebra. This arrangement is the same as in salamanders, and there is no significant variation among the caecilians studied.

\section{M. subvertebralis}

In the majority of caecilians, the $M$. subvertebralis proper consists of a simple series of gently overlapping myomeres. However, the ichthyophiid species are different in that each subvertebral myomere has an elongate, posterior extension (posterior flexure). These flexures, in Ichthyophis glutinosus and Uraeotyphlus narayani, are large and influence two intercentral joints. The flexures are smaller and thinner in I. kohtaoensis and I. orthoplicatus, and are reduced even more extremely in Caudacaecilia nigroflava. The basapophyseal muscles of caecilians so far dissected are nearly uniform in structure, although there are some differences in size, which are not easily quantifiable. 
M. subvertebralis pars ventralis

In the majority of dissected species the pars ventralis of the $M$. subvertebralis originates midventrally along the centra and subcentral keels, and the fibres extend anterolaterally to connect firmly to the musculature of the external sheath (Figs 3(a), (b); 4(a)). All dissected rhinatrematids, ichthyophiids, scolecomorphids, and the majority of caeciliids exhibit this pattern. All available typhlonectids have the pars ventralis originating from fascia, lateral to the centra, although the fascial fibres attach midventrally. The medial margin of the pars ventralis is scalloped, such that muscle fibres extend further medially in the basapophyseal regions (Fig. 4(d)). Two caeciliids, Caecilia nigricans and Oscaecilia ochrocephala, have a similar development of the pars ventralis, but without the scalloping seen in typhlonectids (Figs 3(c), 4(c)). In Hypogeophis rostratus, fibres of this unit converge medially to the basapophyseal regions and some fibres attach to the subcentral keel (Fig. 4(b)).

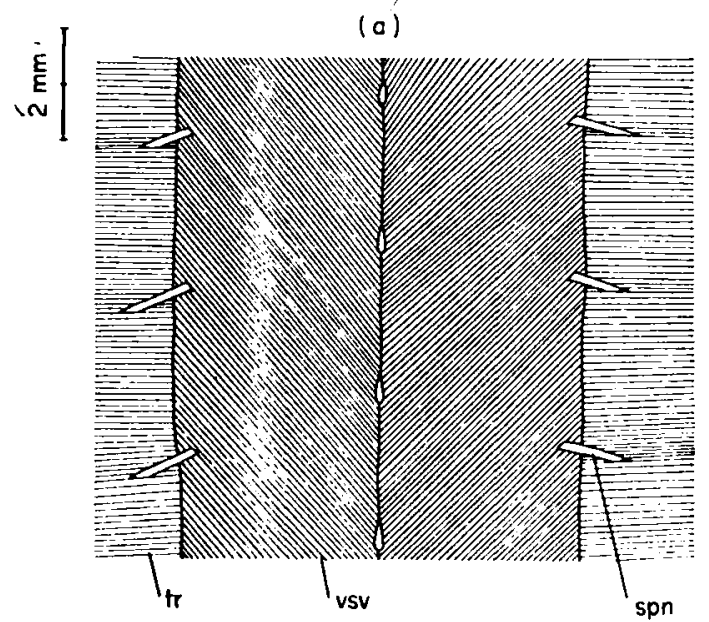

(b)

(c)

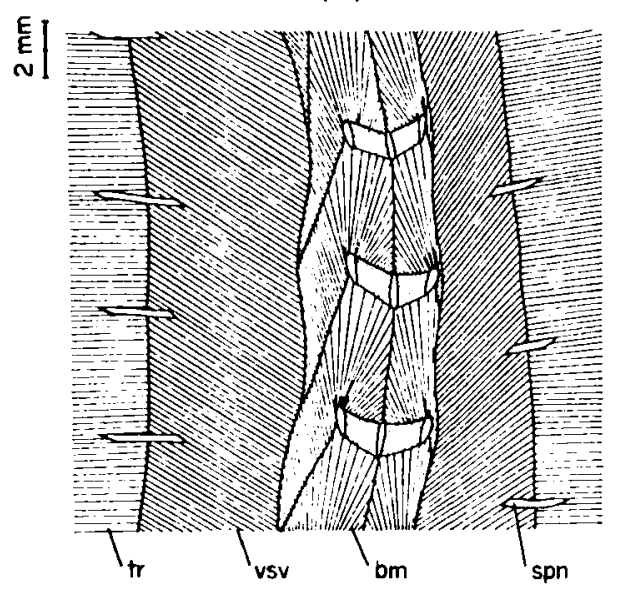

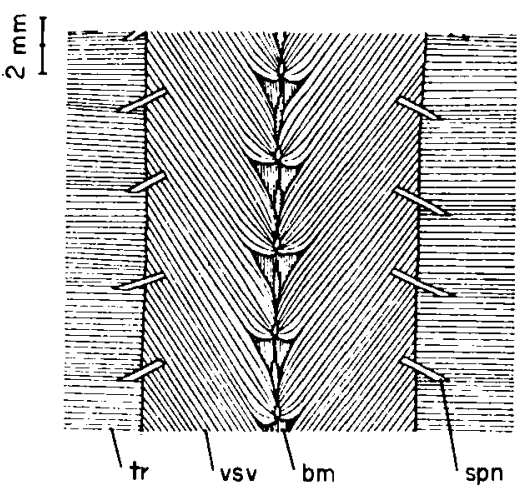

(d)

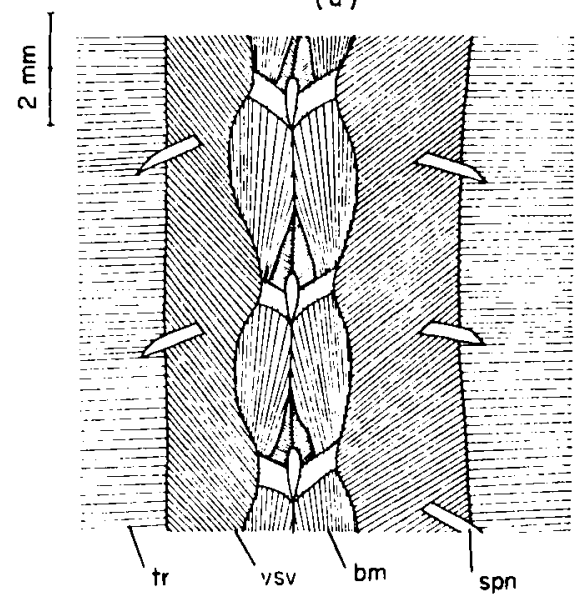

FIG. 4. Ventral view of the pars ventralis of the $M$. subventebralis and associated units. Muscle fibres shown diagrammatically. (a) Geotrypetes seraphini, UMMZ uncatalogued specimen; (b) Hypogeophis rostratus, UMMZ 145410; (c) C'at'ilia nigricans, UMMZ I21035: (d) Typhlonectes sp., UMMZ uncatalogued specimen. (Explanation of abbreviations see p. 398.) 


\section{Discussion}

In this paper we have extended our observations (Naylor \& Nussbaum, 1980) of variation in the trunk musculature of caecilians. Our previous conclusion that both the Rhinatrematidae and Ichthyophiidae have distinctive trunk musculature is upheld. Only rhinatrematids have a $M$. obliquus internus that is segmented by myosepta and that is confluent with the $M$. obliquus externus profundus to form the $M$. rectus abdominis. This is also the only family that does not have significant internal overlap of the $M$. o. e. profundus with the $M$. $r$. abdominis, and that has a combination of one posterior and one anterior flexure internally in the $M$. rectus lateralis. Ichthyophiids are unique in that they have one anterior and two posterior flexures internally in the $M$. r. lateralis, and they are the only caecilians with posterior flexures, or flexures of any kind, in the $M$. subvertebralis.

The remaining three families, Caeciliidae, Scolecomorphidae, and Typhlonectidae, are generally similar in their trunk musculature, but some differences exist. Typhlonectids have a series of character states in the trunk musculature that distinguishes them from other caecilians. The $M$. rectus lateralis is very thin, with little internal overlap between the myomeres except for a single, extremely short posterior flexure. In the dorsal half of each myomere, above the posterior flexure, muscle fibres do not extend the full anteroposterior distance between myosepta, but leave a posterior gap in each segment, a situation not encountered in other families. The pars ventralis of the $M$. subvertebralis does not attach midcentrally, but to fascia. The medial margin of the unit is scalloped distinctly, with fibres extending further medially in the basapophyseal region. Finally, there is less internal overlap of the myomeres of the M. obliquus externus profundus and M. rectus abdominis than occurs in other families, rhinatrematids excepted. This combination of characters correlates, perhaps functionally, with the aquatic habit of typhlonectids. A well-developed, external muscular sheath with extensive internal overlap of segments and a thick $M$. subvertebralis pars ventralis attaching midcentrally are presumably adaptations for burrowing. The absence of such structures from typhlonectids would, therefore, reflect adaptation to aquatic, anguilliform locomotion.

Caeciliids currently are separated into two subfamilies (Taylor, 1969), Caeciliinae and Dermophiinae, the former containing the Neotropical genera Caecilia and Oscaecilia and the latter containing the remaining genera. The trunk musculature of Caecilia nigricans and Oscaecilia ochrocephala generally conforms to that of the dermophiine species, but the former have three features that set them apart. The first is their distinctive pars ventralis of the $M$. vertebralis (Table II), which resembles the same structure in typhlonectids. The second is their very thin $M$. dorsalis trunci. Thirdly, the caeciliines have extensive internal overlap of the myomeres of the $M$. obliquus externus profundus and $M$. rectus abdominis. In dermophiines (also ichthyophiids and scolecomorphids), the internal, posterior flexure extends back for a distance of between one half and one full width of a myomere segment (Naylor \& Nussbaum, 1980, figs 4, 7, 9). In caeciliines, the overlap is greater than that of two myomere segments, as shown in the cross-section of $O$. ochrocephala (Fig. 3(c)), in which the septal divisions appear to divide the M. r. abdominis and M. o. e. profundus into three sections. There is very little variation in trunk musculature among the Dermophiinae examined, except in the degree to which the paired $\mathrm{Mm}$. recti laterales are separated middorsally and the degree of segmentation of the M. obliquus externus superficialis.

Scolecomorphids have no obvious characteristics of their trunk musculature that distinguish them from all other caecilians. 
None of the variation so far encountered in the trunk musculature of caecilians is in strong disagreement with the current classification of the group. Closer examination of the trunk musculature of more species of the Dermophiinae is needed to help determine the relationships among these genera, which are scattered across three continents (South America, Africa, Asia) and one microcontinent (Seychelles Archipelago). The similarity of the trunk musculature of the Scolecomorphidae to that of some of the Dermophiinae may be real or superficial and requires further study.

The axial skeletons and musculature of caecilians, salamanders, and frogs are similar and differ from all other tetrapods in that the ribs do not extend beyond the vertebral musculature into the muscles of the lateral body (some salamanders, e.g., Euproctus and some Triturus do have exceptional ribs that extend slightly into the lateral abdominal musculature) and in the relatively undifferentiated condition of the vertebral musculature. The short ribs of lissamphibians seem to be correlated with their method of breathing, which does not involve expansion of the coelom for inhalation (Cox, 1967), but rather relies on a buccal force pumping mechanism. Aside from these similarities in trunk musculature among the three lissamphibian orders, which may or may not be monophyletically derived, there are also some fundamental differences, which are at least partly related to their different methods of locomotion.

Frogs have a short ( $\leq 9$ trunk vertebrae) and relatively inflexible vertebral column, with greatly reduced vertebral and body wall musculature, compared to caecilians and salamanders (Fig. 3(f); also see Maurer, 1895). The vertebral musculature consists of weakly developed epaxial muscles with no development at all of the hypaxial muscles ( $M$. subvertebralis). Only the $M$. obliquus externus and the $M$. transversus are found in the lateral body wall, with the $M$. rectus abdominis situated ventrolaterally. The reduced trunk musculature of anurans is in keeping with their unusual mode of locomotion. They rely on powerfully developed hindlimbs for both terrestrial and aquatic progression with little contribution from spinal flexion.

Salamanders have vertebral columns of intermediate length (12-63 trunk vertebrae), and they have well-developed vertebral and body wall musculature used for lateral flexion of the spine while swimming or walking. The more elongate salamanders are either aquatic paedomorphs (Amphiuma, Siren) or terrestrial semifossorial forms (Batrachoseps, Oedipina) with reduced limbs and increased reliance on lateral undulation of the vertebral column for locomotion.

Caecilians have long vertebral columns (70-283 vertebrae) and strongly developed trunk musculature. Caecilians may move on the surface, through water, or through loose soil by serpentine flexion of the vertebral column. Movement through preformed burrows may involve either serpentine or vermiform (sensu Gaymer, 1971) locomotion, or both, depending on the characteristics of the burrow. The formation of new burrows in compact soil probably entails only vermiform action. All of these modes of locomotion in caecilians depend on the presence of a supple vertebral column and well-developed trunk muscles.

In regard to trunk musculature, caecilians and salamanders are more similar to each other than either is to frogs, but this may only reflect independent retention of the major features of the primitive mode of locomotion involving lateral undulation of the body. Caecilians and salamanders are similar in that some fully metamorphosed individuals of both groups have four layers of muscle in the lateral body wall, consisting of the $\mathrm{Mm}$. obliquus externus superficialis, o. e. profundus, o. internus, and transversus. Ventrally, both groups have a 
single unit, the $M$. rectus abdominis, although some salamanders (hynobiids, plethodontids, some salamandrids) have their $M . r$. abdominis clearly divided into deep and superficial parts. Dorsolaterally, all caecilians and some salamanders have a $M$. rectus lateralis, which, however, may not be homologous for the two groups. The vertebral musculature of both groups consists of a well-developed $M$. dorsalis trunci and hyperapophyseal units in the epaxial region and a less well-developed hypaxial musculature including the $M$. subvertebralis and the basapophyseal muscles.

Dissection of species sampled from all extant families of salamanders has uncovered a tremendous amount of variation in the $M$. dorsalis trunci, $M$. subvertebralis, and layers of the lateral abdominal musculature (Naylor, 1978). As a unit, the trunk musculature is diagnostic at familial, and often generic, levels and exceeds that encountered in caecilians (see above, also Naylor \& Nussbaum, 1980). Variation in the $M$. subvertebralis of salamanders is especially marked, ranging among three conditions: force directed along anterior and posterior lines from each vertebra (anterior basapophyseal system: hynobiids, cryptobranchids, amphiumids, and ambystomatids); force directed only posteriorly (posterior basapophyseal system: plethodontids, proteids, Salamandra and Chioglossa); or force limited to single intervertebral sections between adjacent transverse processes and ribs (lizard-like: some plethodontids and all pleurodeline salamandrids). By contrast, caecilians present a single, relatively invariant $M$. subvertebralis with anteriorly directed basapophyseal muscles. Except for the presence of large posterior subvertebral flexures in ichthyophiids and variation in insertion of the M. subvertebralis pars ventralis (Table II), differences are difficult to quantify. Similar differences in the amount of variation are encountered between the two orders when the other units of the trunk musculature are considered.

It is difficult to account for the different levels of diversity because of the lack of detailed, functional, morphological studies. Environmental and adaptive correlations are often not evident, except to some degree in salamanders and caecilians of aquatic habit.

Caecilians and salamanders differ in the presence of a pars ventralis of the $M$. subvertebralis in all caecilians that is lacking in all salamanders. However, the M. transversus of the pleurodeline salamandrids extends dorsolaterally to the ventral surface of the vertebral column (Naylor, 1978), thus occupying the same position as the pars ventralis of caecilians and perhaps performing the same function(s). Caecilians and salamanders also differ in the relative size and position of the $M$. rectus lateralis and the $M$. obliquus externus superficialis (Fig. 3(a)-(e)). A more fundamental difference between caecilians and salamanders concerns the relationship between the vertebral musculature and the muscles of the body wall. In caecilians these two groups of muscles are largely independent, but in salamanders, with one exception, the vertebral muscles are tightly bound to the muscles of the body. This can be seen in Fig. 3(d), in which the lateral fibres of the $M$. dorsalis trunci are shown to be continuous with the fibres of both the $M$. obliquus externus profundus and the $M$. obliquus internus. The exceptional salamander is Amphiuma means (Fig. 3(e)), a species with relatively independent vertebral and body wall musculature, resembling that of caecilians.

The similarity of the trunk musculature of caecilians and Amphiuma raises ghosts of past beliefs by Cope $(1867,1886,1895)$, the brothers Sarasin (1887-1890) and others that caecilians and Amphiuma are sister-groups. Cope would have derived caecilians from the amphiumid lineage of salamanders, whereas the Sarasins thought that Amphiuma arose paedomorphically from a caecilian and was not a salamander at all. Kingsley (1902) fairly effectively dealt with these early speculations, and not since then has a gymnophionan- 
amphiumid relationship seriously been considered. Similarities in the trunk musculature of the two groups, like some of the previously reported common features, may be functionally related to the elongate and limbless or nearly limbless body form of the two groups and do not necessarily reflect common descent.

Comparison of what is known about the trunk musculature of the three lissamphibian orders provides no solution to the controversy over whether the Lissamphibia is a natural, monophyletic subclass (e.g., Carroll \& Currie, 1975; Parsons \& Williams, 1963). Derivation of the trunk musculature of caecilians and salamanders from a relatively recent common ancestor is conceivable, but not demanded by the evidence. The trunk musculature of frogs is too highly derived and simplified to be of value in determining the relationships of the group.

\section{Summary}

The trunk muscles of caecilians are relatively invariant. The same muscles are present and similarly positioned in all forms examined, including 28 species in 24 of the 33 known genera. Two groups of trunk muscles, the external muscular sheath and the vertebral muscles, are identified. The external muscular sheath consists of the Mm. obliquus externus superficialis, o. e. profundus, rectus lateralis, o. internus, transversus, and $r$. abdominis. The external muscular sheath, which is bound tightly to the skin, forms a hollow tube surrounding the vertebral muscles and the viscera. The vertebral musculature consists of the $\mathrm{Mm}$. dorsalis trunci, subvertebralis, s. pars ventralis, and the basapophyseal and hyperapophyseal muscles. The external muscular sheath and the vertebral musculature are largely independent, being held together by connective tissue.

On a finer scale, some variation in trunk musculature exists, which generally conforms to taxonomic groups. Some of the variation may be related to identifiable functional modes. For example, the trunk musculature of the fully aquatic typhlonectids is distinctive and suggestive of reduced capacity for burrowing.

The trunk musculature of caecilians is, not surprisingly, more similar to that of salamanders than to that of frogs. Similarities in the trunk musculature of caecilians and salamanders could be explained as independent retention of ancestral characteristics and do not necessarily indicate close relationship. The highly derived and reduced trunk musculature of frogs, which probably is related functionally to the relatively inflexible anuran vertebral column, provides no clues to lissamphibian relationships.

Support for this work was provided by grants from the National Geographic Society and the Horace H. Rackham School of Graduate Studies, The University of Michigan to R.A.N. and an NSERC operating grant to B.G.N.

\section{REFERENCES}

Carroll, R. L. \& Currie, P. J. (1975). Microsaurs as possible apodan ancestors. Zool. J. Linn. Soc. 57: 229-247.

Cope, E. D. (1867). On the structure and distribution of genera of the Arciferous Anura. With a supplement on the osseous structures of the types of the Urodela. J. Acad. nat. Sci. Philad. (2) 5: 97-112.

Cope, E. D. (1886). On the structure and affinities of the Amphiumidae. Proc. Am. phil. Soc. 23: 442-445.

Cope, E. D. (1895). The Batrachia of North America. Bull. U.S. natn. Mus. No. 34: 1-525. 
Cox, C. B. (1967). Cutaneous respiration and the origin of the modern Amphibia. Proc. linn. Soc. Lond. 178: 37-48. Gans, C. (1973). Locomotion and burrowing in limbless vertebrates. Nature, Lond. 242: 414-415.

Gaymer, R. (1971). New method of locomotion in limbless terrestrial vertebrates. Nature, Lond. 234: 150-151. Kingsley, J. S. (1902). The systematic position of the caecilians. Tufts Coll. Stud. 7: 323-344.

Lawson, R. (1965). The anatomy of Hypogeophis rostratus Cuvier (Amphibia: Apoda or Gymnophiona) Part II. The musculature. Proc. Univ. Newcastle-upon-Tyne Phil. Soc. 1: 52-63.

Marcus, H. (1934). Uber den Einfluss des Kriechens auf Wirbelzahl und Organgestalt bei Apoden. Biol. Zbl. 54: $518-522$.

Maurer, F. (1892). Der Aufbau und die Entwicklung der ventralen Rumpfmusculatur bei den urodelen Amphibien und deren Beziehungen zu den gleichen muskeln der Selachier und Teleostier. Morph. Jb. 18: 76-179.

Maurer, F. (1895). Die ventrale Rumpfmuskulatur der anuren Amphibien. Morph. Jb. 22: 225-264.

Maurer, F. (1911). Die ventrale Rumpfmuskulatur von Menobranchus, Menopoma and Amphiuma, verglichen mit den gleichen Muskeln anderer Urodelen. Jena Z. Naturw. 47: 1-42.

Naylor, B. G. (1978). The systematics of fossil and recent salamanders (Amphibia: Caudata), with special reference to the vertebral column and trunk musculature. Ph.D. Dissertation, Univ. Alberta.

Naylor, B. G. \& Nussbaum, R. A. (1980). The trunk musculature of caecilians (Amphibia: Gymnophiona). $J$. Morph. 166: 259-273.

Nishi, S. (1916). Zur vergleichenden Anatomie der eigentlichen Ruckenmuskeln. Morph. Jb. 50: 167-318.

Nishi, S. (1938). Muskeln des Rumpfes. In Handbuch der vergleichenden Anatomie der Wirbeltiere 5: 351-446. Bolk, L., Goppert, E., Kallius, E. and Lubosch, W. (Eds). Berlin: Urban and Schwarzenberg.

Nussbaum, R. A. (1977). Rhinatrematidae: a new family of caecilians (Amphibia: Gymnophiona). Occ. Pap. Mus. Zool. Univ. Mich. No. 682: 1-30.

Nussbaum, R. A. (1979). The taxonomic status of the caecilian genus Uraeotvphlus Peters. Occ. Pap. Mus. Zool. Univ. Mich. No. 687: 1-20.

Parsons, T. S. \& Williams, E. E. (1963). The relationships of the modern Amphibia: A re-examination. $Q$. Rev. Biol. 38: 26-53.

Sarasin, P. \& Sarasin, F. (1887-90). Ergebnisse naturwissenschaftichen Forschungen auf Ceylon in den Jahren 1884-1886. Zur Entwicklungsgeschichte u. Anat. der Cevlonische Blindwuhle, Ichthyophis glutinosus. Weisbaden: Kreidel.

Schnurbein, A. F. von (1935). Der Bewegungsapparat von Hypogeophis. Beitrag zur Kenntnis der Gymnophionen XXIII. Morph. Jb. 75: 315-330.

Taylor, E. H. (1922). Additions to the herpetological fauna of the Philippine Islands, III. Philipp. J. Sci. 22: $515-558$.

Taylor, E. H. (1969). Skulls of Gymnophiona and their significance in the taxonomy of the group. Kans. Univ. Sci. Bull. 48: 585-687.

Wiedersheim, R. (1879). Die Anatomie der Gymnophionen. Jena: Gustav Fischer.

\section{Abbreviations used in figures}

$\begin{array}{ll}\text { bm } & \text { basapophyseal muscle } \\ \text { dt } & \text { M. dorsalis trunci } \\ \text { ems } & \text { external muscular sheath } \\ \text { oe } & \text { M. obliquus externus } \\ \text { oep } & \text { M. obliquus externus profundus } \\ \text { oes } & \text { M. obliquus externus superficialis } \\ \text { oi } & \text { M. obliquus internus }\end{array}$

bm basapophyseal muscle

dorsalis trunci

oe M. obliquus externus

oi $M$. obliquus internus

$\begin{array}{ll}\text { ra } & \text { M. rectus abdominis } \\ \mathrm{rl} & M . \text { rectus lateralis } \\ \text { spn } & \text { spinal nerve } \\ \mathrm{sv} & M . \text { subvertebralis } \\ \mathrm{tr} & M . \text { transversus } \\ \mathrm{vm} & \text { vertebral musculature } \\ \text { vsv } & M . \text { subvertebralis pars ventralis }\end{array}$

